\title{
Mapping of mechanical properties at microstructural length scale in WC-Co cemented carbides: Assessment of hardness and elastic modulus by means of high speed massive nanoindentation and statistical analysis
}

\author{
J.J. Roa ${ }^{1,2, *}$, P. Sudharshan Phani ${ }^{3}$, W.C. Oliver ${ }^{4}$, L. Llanes ${ }^{1,2}$ \\ ${ }^{1}$ Center for Research in Structural Integrity, Micromechanics and Reliability of Materials (CIEFMA), \\ Department of Materials Science and Metallurgical Engineering, Universitat Politècnica de Catalunya \\ (UPC), EEBE, 08019 Barcelona, Spain. \\ ${ }^{2}$ Barcelona Research Center in Multiscale Science and Engineering. Universitat Politècnica de Catalunya \\ (UPC), 08019 Barcelona, Spain. \\ ${ }^{3}$ International Advanced Research Centre for Powder Metallurgy and New Materials (ARCI), Balapur \\ PO, 500005, Telangana, India. \\ ${ }^{4}$ Nanomechanics, Inc. TN 37830 Oak Ridge, USA. \\ * Corresponding author, e-mail: joan.josep.roa@upc.edu
}

\begin{abstract}
This paper studies the correlation between the microstructure and the mechanical properties at the nanometric length scale of individual WC grains as well as the metallic cobalt binder in cemented carbide systems. The local crystallographic orientation has been determined by electron backscattered diffraction and the microstructural analysis has been performed using field emission scanning electron microscopy. Small-scale hardness and elastic modulus have been assessed by means of high speed massive nanoindentation and subsequent statistical analysis. The attained mechanical property mappings present a clear correlation between local hardness and stiffness with chemical nature for each constitutive phase as well as with the crystallographic orientation for the WC particles. Besides expected findings associated with individual phases, such as clear anisotropy of the ceramic phase (basal plane being harder and stiffer than the prismatic one) and relatively high flow stress for constrained binder, the protocol implemented provides novel information on local mechanical response at interfaces between ceramic particles with different orientations as well as regions within the metallic cobalt binder close to the WC-Co interface.
\end{abstract}

Keywords: cemented carbides; nanoindentation; massive indentation; statistical method; mechanical mapping; mechanical anisotropy; hardness; elastic modulus 


\section{Introduction}

The unique combination of hardness, toughness and wear resistance exhibited by tungsten carbide - cobalt (WC-Co) cemented carbides (usually referred to as hardmetals) has made them a preeminent material choice for extremely demanding applications, such as metal cutting/forming tools or mining bits, where improved and consistent performance together with high reliability are required [1]. This is a direct consequence of the composite character of these materials which permits to benefit from both: (1) outstanding intrinsic properties of the individual phases, including the plasticlike nature of WC as compared with other monocarbides, as well as fcc-hcp phase transformation in the binder (Co-W-C eutectic) as an additional micromechanism for damage tolerance, and (2) synergic effects of their combined response, on the basis of optimal interface properties $[2,3]$.

Regarding the mechanical response of the individual phases constituting hardmetals, earlier studies mainly concentrated on the assessment of plastic properties within isolated WC single crystals $[4,5,6,7,8]$. With the advent of micro- and nano-indentation techniques, investigations with similar objectives have been expanded towards measurement of local properties for the ceramic phase within the composite system itself $[8,9,10,11,12,13,14,15,16]$. In general, all of them report a clear hardness anisotropy behavior of WC particles at nanometric length scale, highlighted in recent studies by the novel combination of electron-backscattered diffraction (EBSD) and discrete nanoindentation events [14-16]. Recently, Roa et al. [17,18] have attained more detailed information on the small-scale properties of WC-Co materials by including statistical analysis of massive nanoindentation data. It has allowed (1) to get a statistically significant value of the intrinsic hardness of the Co-base binder constrained by the WC grains [17]; and (2) to validate the existence of a Hall-Petch relationship for these materials on the basis of the binder mean free path, pointing then out this parameter as the effective microstructural length scale for studying phase boundary strengthening [18].

Within the above framework, the present study aims for implementation of novel highspeed and micromechanical mapping (hardness and elastic modulus) experimental upgrades in the massive nanoindentation approach, based on the use of smaller penetration depths, and thereby closer spacing of indents in order to enhance the 
accuracy in the micromechanical properties determination for each constitutive phase of heterogeneous hard materials (WC and Co). It finally allows to enhancing accuracy and statistical significance of the data attained, including assessment of values corresponding to smaller length scale regions than individual phases themselves, i.e. those where interface-related response takes place.

\section{Experimental procedure}

An experimental WC-Co composite grade supplied by Sandvik Hyperion (Coventry, United Kingdom) was used in this study. Carbide contiguity and binder mean free path were deduced according to empirical relations from open literature [2,19,20]. The corresponding microstructural parameters are summarized in Table 1.

Nanoindentation tests were performed using a commercially available nanoindenter, iMicro® from Nanomechanics Inc., Oak Ridge, USA. Multiple large indentation maps with 10000 indents per map on a $50 \times 50 \mu \mathrm{m}^{2}$ area was performed to a maximum load of $4 \mathrm{mN}$. In all 200000 indents (90000 indents made in a region mapped by EBSD in order to determine the hardness and elastic modulus anisotropy, see Figure 1) were performed using a high speed mechanical property mapping technique, NanoBlitz, wherein each test takes less than $1 \mathrm{~s}$ to perform. This includes positioning the sample under the tip, approaching the surface, loading, unloading and retracting. From the load and depth data at each test location, contact stiffness, hardness and modulus can be calculated using the standard Oliver and Pharr method [21,22]. The fast testing capability enables mapping over large areas in a short amount of time and also access to large data sets for statistical analysis. A diamond Berkovich tip was used for all the tests because it allows to extract directly hardness and elastic modulus by using the methodology proposed by Oliver and Pharr [21,22]. The load frame stiffness determination and tip area calibration was done using the results of constant strain rate tests $\left(0.2 \mathrm{~s}^{-1}\right)$ on fused silica. For these tests, the contact stiffness was continuously measured as a function of depth using a phase lock amplifier oscillating at $100 \mathrm{~Hz}$ frequency and a $2 \mathrm{~nm}$ displacement amplitude.

WC grains chosen for these tests corresponded to those with well-defined crystal orientation, i.e. either basal or prismatic, with respect to indentation axis. Such orientation information was obtained through electron back-scattered diffraction (EBSD) analyses, carried out using a field emission scanning electron microscope 
(FESEM) JEOL 7001F equipped with an orientation imaging microscopy system. EBSD measurements were performed with a constant step size of $200 \mathrm{~nm}$, at an accelerating voltage of $20 \mathrm{kV}$ and beam probe current up to $9 \mathrm{nA}$ (see Figure 1b).

In order to directly determine the intrinsic mechanical properties in terms of hardness and elastic modulus for each constitutive phase, a statistical analysis was performed on a large data set comprising of 200000 indents, according to the method proposed by Ulm and coworkers $[23,24,25,26]$, where the experimental data were treated with a Gaussian distribution. The maximum indentation load and the distance between two neighboring indents were chosen as $4 \mathrm{mN}$ and $500 \mathrm{~nm}$, respectively. Such parameters guarantee each indentation to be treated as an independent statistical event, as results were not affected by neighboring indents. In this particular case, the hardness and elastic modulus maps can be easily reconstructed from the large closely spaced indentation grid. The discrete values are interpolated using a bicubic interpolation between measurement points. Such an interpolation method was chosen since it leads to smoother images.

\section{Results and discussion}

\subsection{Statistical analysis of indentation data}

In this section, we present the results of the large number of indentation tests and the associated statistical analysis. Figure 2, shows the mechanical property histogram (hardness, Figure 2a, and elastic modulus, Figure 2b, with a constant bin size of 0.5 and $25 \mathrm{GPa}$, respectively), calculated from 200000 indents. The histogram presents two peaks centered at around 10 and $25 \mathrm{GPa}$ for the hardness histogram (Figure 2a) and around 230 and $470 \mathrm{GPa}$ for the elastic modulus histogram (Figure 2b). The major peak is unambiguously attributed to the WC particles, while the other peak is related to the constrained metallic binder. This bimodal trend is in good agreement with results obtained by nanoindentation in WC-Co reported by Gee et al. [27]. Furthermore, by applying the statistical method proposed by Ulm and co-workers [23-26] on the experimental values shown in Figure 2, it is possible to further deconvolute the experimental data into five different peaks with different mean values as summarized in Table 2. The higher peak values for both histogram representations, at about $32.5 \pm 3.5$ and $25.5 \pm 5.0 \mathrm{GPa}$ for the hardness and $650 \pm 60$ and $475 \pm 80 \mathrm{GPa}$ for the elastic modulus, are mainly attributed to the basal and prismatic planes. These results are in fair 
agreement with results reported in the literature [17,28,29,30,31,32,33] for the respective planes. The intermediate peaks (centered at around 18.0 \pm 3.5 and $14.0 \pm 4.5$ $\mathrm{GPa}$ and $350 \pm 60$ and $290 \pm 45 \mathrm{GPa}$ for the hardness and elastic modulus, respectively), are related to the hardness response for the interaction between the $\mathrm{WC}-\mathrm{Co}_{\text {composite }}$ and the $\mathrm{WC}_{\text {prismatic plane }}$ which is the dominant $\mathrm{WC}$ phase heterogeneously distributed in the WC-Co system as clearly shown in the EBSD image (blue and green colors in the local crystallographic legend) reported in Figure $\mathbf{1 b}$ and the mechanical interaction between the WC particles and the metallic binder, respectively. Finally, the lowest values centered at $8.0 \pm 5.0 \mathrm{GPa}$ and $200 \pm 75 \mathrm{GPa}$ corresponds to the hardness and elastic modulus of the metallic binder. From the hardness of the metallic binder shown in Table 2 and by using a constraint factor of 3, the flow stress for the constrained binder is found to be around $2.6 \mathrm{GPa}$, which is in agreement with the data reported by Roa et al. $[17,18]$ and Sigl and Fischmeister [34].

Figure 2c shows a SEM image of a representative indent (inside the white dashed circle) corresponding to each of the deconvoluted peaks shown in Figure 2a. Gaussian distribution was chosen for the deconvolution based on the earlier work of Ulm et al. [23-26].

It must be noted that the Gaussian peak deconvolution employing the methodology proposed by Ulm and co-workers [23-26] gives area fractions of $17 \pm 3 \%$ for the metallic binder and $83 \pm 5 \%$ for the WC particles. The value obtained for the metallic binder is slightly higher than the nominal weight fraction provided by the supplier and reported in Table 1 which may be due to the local variation of the distribution of the cobalt binder.

\subsection{Mechanical property mapping}

Hardness and elastic modulus maps are presented here for a better understanding of the mechanical properties histograms presented in Figure 2a and 2b. 9 different hardness and elastic modulus maps performed on the WC-Co specimen are presented in Figure 3. EBSD maps at these locations were collected prior to indentation. Each map has 10000 indents performed to $4 \mathrm{mN}$ load organized in a regular square-shaped grid with a $0.5 \mu \mathrm{m}$ spacing. These indents, as well as the grains of the sample, have been identified by optical microscopy as shown in Figure 1a. Hardness and elastic modulus maps, 
obtained from a bicubic interpolation in between measurement points, is plotted in Figure 3. A clear correlation between the mechanical properties and microstructure is evident from the figure. A zoomed view of a small region is presented in Figure 4, which shows three different regions distinguished by either different chemical nature (metallic binder and ceramic carbides) or distinct carbide crystal orientation (i.e. carbides with surface normal perpendicular to either basal or prismatic planes) and the corresponding hardness and elastic modulus maps which is in agreement with the different peaks presented in Figure 2a and $\mathbf{2 b}$.

From the direct observation of the hardness and elastic modulus maps presented in Figure 3, it is evident that the WC particles are strongly anisotropic, both in terms of hardness and elastic modulus; in agreement with hardness anisotropy reported in the literature for WC crystals [28-32,35]. Furthermore, the hardness and elastic modulus of the metallic binder (blue region corresponds to the metallic Co binder) are $8 \pm 5.5$ and $200 \pm 75 \mathrm{GPa}$, respectively. The hardness value is around eight times higher than that reported in the literature for the pure Co element as shown in Ref. [36]. This difference may be related to two different phenomena: (1) the unconstraint effect generated by the hard and stiff ceramic WC particles; and (2) the presence of C and W atoms dissolved as solid solution in the Co binder. On the other hand, the hardness value is also around 1.5 and 5 times higher than those previously reported by Roa et al. [37] and Roebuck et al. [2] in model-like alloys, respectively. The main reason for such a difference is the constraining effect exerted on the metallic binder by the surrounding carbides. On the other hand, the elastic modulus values observed in the present study are in fair agreement with those determined on nanostructured cobalt [38]. Very interesting, near the $\mathrm{WC} / \mathrm{Co}$ interface, both mechanical properties are slightly higher than in the metallic binder itself; reaching values of around 15 and $350 \mathrm{GPa}$ for hardness and elastic modulus, respectively. This trend may be related to two different phenomena related to the WC-Co interface: (1) the presence of a $500 \mathrm{~nm}$ layer of cobalt with lower tungsten concentration than the bulk cobalt as predicted in Refs. [39,40], and (2) it could be due to the deformation fields not being confined to a single constitutive phase. The composite hardness directly observed from the maps (see Figure 3b) are in agreement with those reported by Roa et al. [17] and determined at the micrometric length scale at a maximum displacement into surface of $2000 \mathrm{~nm}$ (or until reaching the maximum applied load, $650 \mathrm{mN}$ ). However, the hardness and elastic modulus maps reported in the 
present study, provides valuable information at the interface between the ceramic WC particle and the constrained metallic binder. Furthermore, it may be noted that these values have never been reported for a ceramic/metallic composite system.

\subsection{Mechanical anisotropy}

In order to investigate the hardness and elastic modulus anisotropy observed in Figure 3, four small indentation maps of 100 indents (10 by 10) at $4 \mathrm{mN}$ of maximum applied load were analyzed along with the corresponding EBSD maps. Figure 5 shows the FESEM micrographs (Figure 5a and 5c) and the corresponding local crystallographic map overlaid on the image quality maps determined by means of EBSD for the WC particles showing the normal direction orientation, ND (Figure 5b and 5d), for two of the four maps used in this analysis (the other two maps to evaluate the anisotropy effect are not shown here).

By combining the data presented in Figure 3 and 5, it may be concluded that the WC particles are strongly anisotropic in terms of hardness and elastic modulus. Within this context, the WC particles with an orientation near the basal plane are harder and at the same time stiffer than the particles with a prismatic orientation. The basal and prismatic particles have hardness around 28-35 and 20-28 GPa respectively and elastic modulus around 500-700 and 350-500 GPa, respectively. The different trends observed for the hardness and elastic modulus maps are in fair agreement with the values directly obtained by using the statistical method presented in section 3.1.

The mechanical property anisotropy can be analyzed by plotting the variation in hardness and elastic modulus with respect to the misorientation of each grain from the basal plane. This misorientation angle can be calculated using the following equation:

$$
\cos \alpha=\frac{h_{1} h_{2}+\frac{1}{2}\left(h_{1} k_{2}+K_{1} h_{2}\right)+\frac{1}{3} l_{1} l_{2}\left(\frac{c}{a}\right)^{2}}{\sqrt{h_{1}^{2}+k_{1}^{2}+h_{1} k_{1}+\left(\frac{l_{1}}{3}\right)\left(\frac{c}{a}\right)^{2}} \sqrt{h_{2}^{2}+k_{2}^{2}+h_{2} k_{2}+\left(\frac{l_{2}}{3}\right)\left(\frac{c}{a}\right)^{2}}}
$$

where $\alpha$ is the angle between the basal plane (0001) and the grain of interest with Miller indexes (hkil), $c$ and $a$ are the lattice parameters for the WC grains taken as 0.2906 and $0.2837 \mathrm{~nm}$, respectively [2]. The subindex 1 and 2 denote the two planes between which 
the angle is calculated, one being the grain of interest and the other being the basal plane in this case.

The mechanical property anisotropy for WC grains is summarized in Figure 6. In this figure, $\alpha_{0001}$ close to $0^{\circ}$ represents the basal plane, while $\alpha_{0001}$ close to $90^{\circ}$ represents the prismatic plane. The hardness values for the planes close to the basal plane (parallel to the surface) are slightly higher than those close to the prismatic plane (edge to the surface). The (0001) plane shows a value close to $31.5 \mathrm{GPa}$, while, (10 10$)$ and (2 $\overline{1} \overline{1} 0)$ planes show hardness values between 22.5 and $27.5 \mathrm{GPa}$, for both crystallographic planes. This trend is in agreement with the data presented earlier as well as with a previous study by Roebuck et al. [41] using Vickers indentation. Between $10^{\circ}$ to $20^{\circ}$ from the $(0001)$ plane, the variation in the mechanical properties is quite significant. The mechanical response of the WC grains in the present study can be separated into three different trends based on the tilt relative to the basal plane as shown in Figure 6. The first region, denoted as (A) corresponds to the grains slightly misoriented from the basal plane. These grains are the hardest as the compression axis is normal to the slip plane. The second region, denoted as (B), corresponds to indents performed not entirely inside individual WC particles, but close to the interface between two different WC particles with different crystallographic orientations (one oriented in the basal plane "Region A" and the other in the pyramidal and/or prismatic one "Region C'). In this region, the hardness decreases when the tilt relative to the basal plane increases reaching a minimum value at around $22.3^{\circ}$. In that region, only one family of dislocations are responsible for the deformation mechanisms, which correspond to the basal plane traces. Beyond that, the mechanical properties remain mostly constant for a wide range of misorientation angles close to the pyramidal and prismatic planes of the WC grains. In terms of plastic deformation mechanisms, the region $\mathrm{C}$ has a lower and constant hardness value due to two different sets of active slip planes at the same time for a relative misorientation higher than $22.3^{\circ}$, which corresponds to (0001) and $(11 \overline{2} 0)$ planes. This results in lower hardness for the pyramidal and prismatic grains as reported in Refs. [42,43,44].

Prior works (see Refs. [2,17]) have reported that reliable assessment of the intrinsic hardness for the constrained metallic binder required further analysis due to the fact that length scale ratio between nanoindentation depth and binder mean free path being relatively high and the values reported were affected by the surrounding carbides 
particles. However, as it is clearly evident in the maps presented in this work, the hardness and also the elastic modulus increase when the residual impression is closer to the WC/Co interface as it is depicted in Figure 7. This phenomenon may be related to the elastic and plastic flow interaction with the harder and stiffer WC particles as well as the contact area which is function of the depth is not right due to difference on height between both phases.

\section{Conclusions}

From the main findings reported in this study, the following conclusions may be drawn:

(i) Extensive hardness and elastic modulus mapping has been carried out using high speed nanoindentation based mapping technique and compared with the WC-Co microstructure in the indented area determined by EBSD mapping.

(ii) Strong correlations have been observed between the mechanical properties (hardness and elastic modulus) and the constitutive phases as well as the crystallographic orientation for the ceramic particles.

(iii) A statistical analysis of the large data set enables determination of the mechanical properties for each constitutive phase through peak deconvolution.

(iv) The combination of mapping and statistical analysis enables determination of mechanical properties at the interface between two different orientations of the ceramic particles and the metallic cobalt binder near the WC-Co interface.

\section{Acknowledgements}

The current study was supported by the Spanish Ministerio de Economía $y$ Competitividad through Grant MAT2015-70780-C4-P (MINECO/FEDER).

\section{References}

[1] Upadhyaya GS. Cemented tungsten carbides: production, properties and testing. Noyes Publications, New Jersey, USA, 1998.

[2] Roebuck B, Almond EA. Deformation and fracture process and the physical metallurgy of WC-Co hardmetals. Int Mat Rev, 1988;33:90-110. 
[3] Exner HE. Physical and chemical nature of cemented carbides. Int Met Rev 1979; $4: 1149-73$.

[4] Pons L. Plastic properties in tungsten carbides, anisotropy in single-crystal refractory compounds. Vahlidiek, Fred W., Mersol, Stanley A, New York, 1968.

[5] French TD, Thomas DA. Hardness anisotropy and slip in WC crystals. Trans. Metal. Soc. AIME. 1965;233:950-2.

[6] Takahashi FE, Freise EJ. Determination of the slip system in single crystals of tungsten monocarbide. Philos. Mag. 1964;12:1-8.

[7] Pons L, Vahliek FW. Plastic properties in tungsten monocarbide, anisotropy in single-crystal refractory compounds. New York: Plenum, Mersol SA, editors, 1968, pp.: $393-444$.

[8] Lee M. High temperature hardness of tungsten carbide. Met. Trans. A. 1983;14:1625-29.

[9] Cuadrado N, Casellas D, Llanes L, Gonzalez I, Caro J. Effect of crystal anisotropy on the mechanical properties of WC embedded in WC-Co cemented carbides. EuroPM2011-Hard Materials, CD; 2011.

[10] Duszová A, Halgas R, Bl'anda M, Hvizdos P, Lofaj F, Dusza J, Morgiel J. Nanoindentation of WC-Co hardmetals. J. Eur. Ceram. Soc. 2012;33:2227-32.

[11] Gee MG. Constituent phase nanoindentation of $\mathrm{WC} / \mathrm{Co}$ and $\operatorname{Ti}(\mathrm{C}, \mathrm{N})$ hard metals. Mater. Sci. Eng. A. 1996;206:128-36.

[12] Gee MG, Roebuck B, Lindahl P, Andren H-O. Constituent phase nanoindentation of WC/Co and Ti(C,N) hard metals. Mat. Sci. Eng. A. 1996;209:128-36.

[13] Bonache V, Rayón E, Salvador MD, Busquets D. Nanoindentation study of WC12Co hardmetals obtained from nanocrystalline powders: Evaluation of hardness and modulus on individual phases. Mat. Sci. Eng. A. 2010;527:2935-41.

[14] Rayón E, Bonache V, Salvador MD, Roa JJ, Sánchez E. Hardness and Young’s modulus distribution in atmospheric plasma sprayed WC-Co coatings using nanoindentation. Surf. Coat. Technol. 2011;205:4192-97.

[15] Roebuck B, Klose P, Mingard KP. Hardness of hexagonal tungsten carbide crystals as a function of orientation. Acta Mater 2012;60:6131-43.

[16] Csanádi T, Bl'anda M, Chinh NQ, Hvivdos P, Dusza J. Orientation dependent hardness and Nanoindentation induced deformation mechanisms of WC crystals. Acta Mater 2015;83:397-407. 
[17] Roa JJ, Jimenez-Pique E, Verge C, Tarragó JM, Mateo A, Fair J, Llanes L. Intrinsic hardness of constitutive phases in WC-Co composites: Nanoindentation testing, statistical analysis, WC crystal orientation effects and flow stress for the constrained metallic binder. J Eur Ceram Soc 2015;35:3419-25.

[18] Roa JJ, Jimenez-Pique E, Tarragó JM, Sandoval DA, Mateo A, Fair J, Llanes L. Hall-Petch strengthening of the constrained metallic binder in WC-Co cemented carbides: Experimental assessment by means of massive nanoindentation and statistical analysis. Mat Sci Eng A 2016;676:487-91.

[19] Roebuck B, Almond EA. Deformation and fracture processes and the physical metallurgy of WC-Co hardmetals. Int Mater Rev 1988;33:90-110.

[20] Tarragó JM, Coureaux D, Torres Y, Wu F, Al-Dawery I, Llanes L. Implementation of an effective time-saving two-stage methodology for microstructural characterization of cemented carbides. Int J Refract Met Hard Mater 2016;55:80-86.

[21] Oliver WC, Pharr GM. An improve technique for determining hardness and elastic modulus using load and displacement sensing indentation experiments. J Mat Res. 1992; 7:1564-83.

[22] Oliver WC, Pharr GM. Measurement of hardness and elastic modulus by instrumented indentation: Advances in understanding and refinements to methodology. J Mat Res. 2004;19:3-20.

[23] Constantinides G, Ulm F-J, Van Vliet K. On the use of Nanoindentation for cementitious materials. Mater Struct 2003;36:191-6.

[24] Constantinides G, Chandran KSR, Ulm F-J, Van Vliet K. Grid indentation analysis of composite microstructure and mechanics: principles and validation. Mater Sci Eng A 2006; A430:189-202.

[25] Constantinides G, Ulm F-J. The nanogranular nature of C-S-H. J Mech Phys Solids 2006;55:64-90.

[26] Ulm F-J, Vandamme M, Bobko C, Ortega JA, Tai K, Ortiz CJ. Statistical indentation techniques for hydrated nanocomposites: concrete, bone, and shale. J Am Ceram Soc 2007;90:2677-92.

[27] Gee MG, Roebuck B, Lindahl P, Andren H-O. Constituent phase nanoindentation of WC/Co and Ti(C,N) hard metals. Mater Sci Eng A 1996;A209:128-36.

[28] French DN, Thomas D. Hardness anisotropy and slip in WC crystals. Trans AIME 1965;233:950-2. 
[29] Lee M. High temperatura hardness of tungsten carbide. Metall Trans A 1983;14A:1625-9.

[30] Cuadrado N, Casellas D, Llanes L, González I, Caro J. Effect of crystal anisotropy on the mechanical properties of WC embedded in WC-Co cemented carbides. In: Euro PM2011-hard materials. 2011, p.215-20.

[31] Roebuck B, Klose P, Mingard KP. Hardness of hexagonal tungsten carbide crystals as a function of orientation. Acta Mater 2012;60:6131-43.

[32] Duszová A, Halgas R, Bl'anda M, Hvizdos P, Lofaj F, Dusza J, et al. Nanoindentation of WC-Co hardmetals. J Eur Ceram Soc 2013;33:2227-32.

[33] Csanádi T, Bl'anda M, Chinh NQ, Hvivdos P, Dusza J. Orientation dependent hardness and Nanoindentation induced deformation mechanisms of WC crystals. Acta Mater 2015;83:397-407.

[34] Sigl LS, Fischmeister HF. On the fracture toughness of cemented carbides. Acta Metall 1988;36:887-97.

[35] Pons L. Plastic properties in tungsten monocarbide. In: Vahldiek FW, Mersol SA, editors. Anisotropy in single-crystal refractory compounds, vol. 2. New York: Plenum; 1968. p.393-444.

[36] Davis JR. Handbook Committee, ASM International (200-05-01). "Cobalt". Nickel, cobalt, and their alloys. P.354. ISBN 978-0-87170-685-0.

[37] Roa JJ, Jimenez-Pique E, Tarragó JM, Zivcec M, Broeckmann C, Llanes L. Berkovich Nanoindentation and deformation mechanisms in a hardmetal binder-like cobalt alloy. Mat Sci Eng A. 2015;621:128-32.

[38] Barry AH, Dirras G, Schoenstein F, Tétard F, Jouini N. Microstructure and mechanical properties of bulk highly fauled fcc/hcp nanostructured cobalt microstructures . Mater. Charact. 2014;91:26-33.

[39] Hellsing, M. High resolution microanalysis of binder phase in as-sintered WC-Co cemented carbides. Mater. Sci. Technol. 1988;4:824-829.

[40] Gant AJ, Gee MG, May AT. The evaluation of tribo-corrosion synergy for WC-Co hardmetals in low stress abrasion. Wear. 2004;256:500-516.

[41] Roebuck B, Klose P, Mingard KP. Hardness of hexagonal tungsten carbide crystals as a function of orientation. Acta Mater. 2012;60: 6131-43.

[42] T. Johannesson T, Lehtinen B. On the Plasticity of Tungsten Carbide. Phys. Stat. Sol.A 1973;16:615-22. 
[43] Greenwood RM, Loretto MH, Smallman RE. The defect structure of tungten carbide in deformed tungsten crbide-cobalt composites. Acta Metall. 1982; 30:1193-6.

[44] Bartolucci S, Schlössin HH. Plastic deformation preceding fracture in tungsten carbide-cobalt alloys. Acta Metall. 1966;14:337-9. 


\section{Figure captions}

Figure 1. (a) Optical micrograph showing the 9 different maps on which a total of 90000 indents were performed and $(b)$ local crystallographic map obtained by means of EBSD of the same region

Figure 2. Mechanical property histogram determined from 200000 indents performed to a maximum applied load of $4 \mathrm{mN}$. The (a) hardness and (b) elastic modulus histograms are calculated with a constant bin size of 0.5 and $25 \mathrm{GPa}$, respectively. The deconvoluted distributions obtained by the statistical analysis (summarized in Table 2) are overlapped on both the histograms. (c) FESEM micrographs of representative indents for each deconvoluted peak labeled in Figure 2a.

Figure 3. (a) Hardness map and (b) elastic modulus map of the region of a large area mapped by EBSD.

Figure 4. Local crystallographic orientation and mechanical properties map (hardness and elastic modulus) for a WC particle (labelled as (a) and highlighted by a dash square in map 2, Figure 1a), oriented in a crystallographic orientation near the basal plane.

Figure 5. (a) and (c) FESEM micrograph, and (b) and (d) Local crystallographic orientation of two different indentation arrays of 100 indents (10 by 10) performed to $4 \mathrm{mN}$ of maximum load. Pixel size: 50 nm.

Figure 6. (a) Hardness and (b) elastic modulus as a function of misorientation angle with respect to the basal plane for WC particles.

Figure 7. (a) Hardness map and (b) elastic modulus map overlapped on the optical image clearly showing the locations of the indents. 
(a)

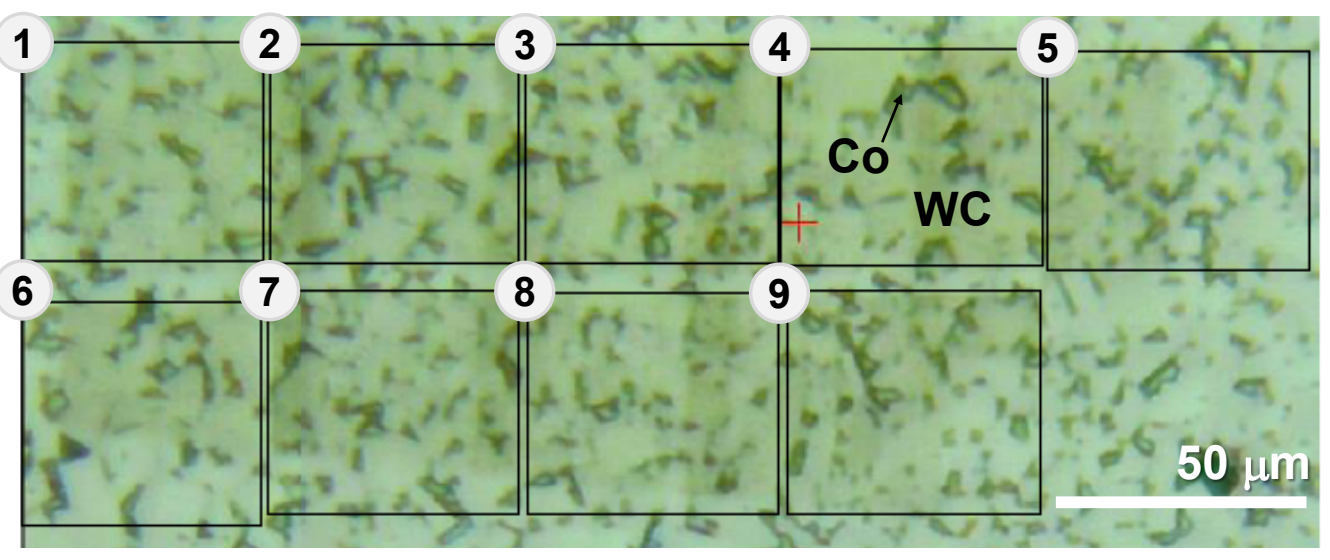

(b) $1 \mathrm{x}-2$

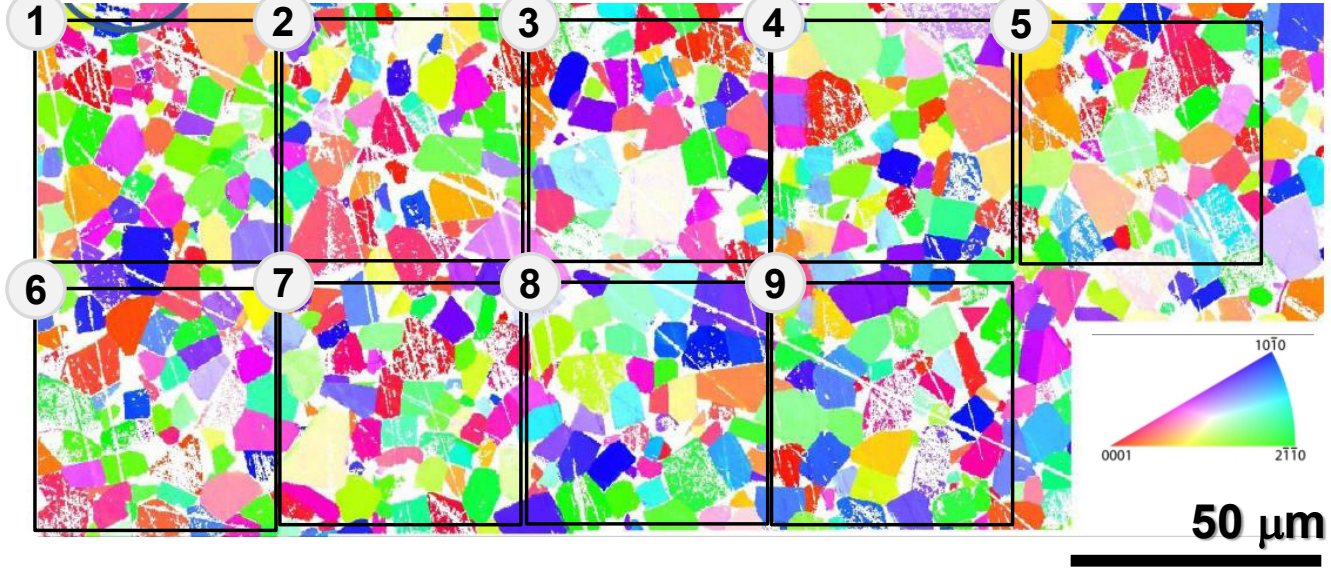

Figure 1 
(a)

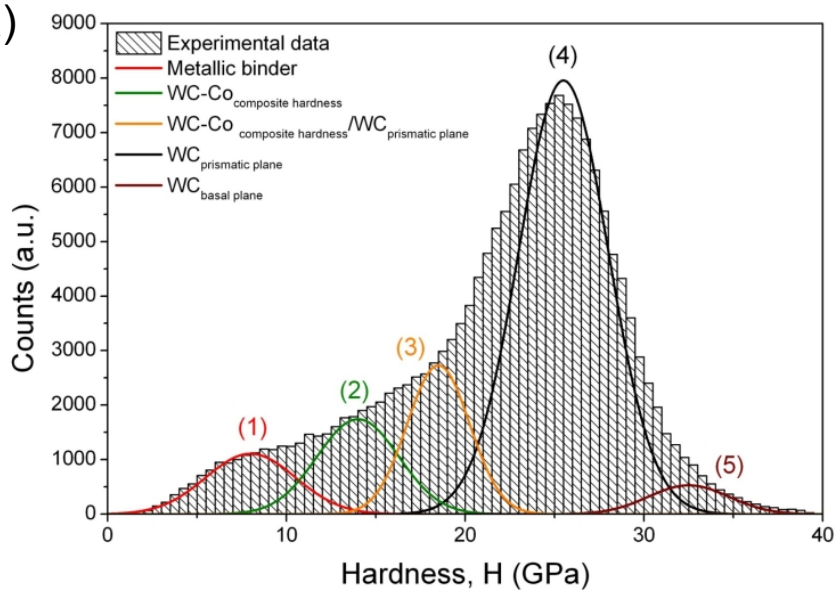

(b) ${ }^{30000}$ Experimental values

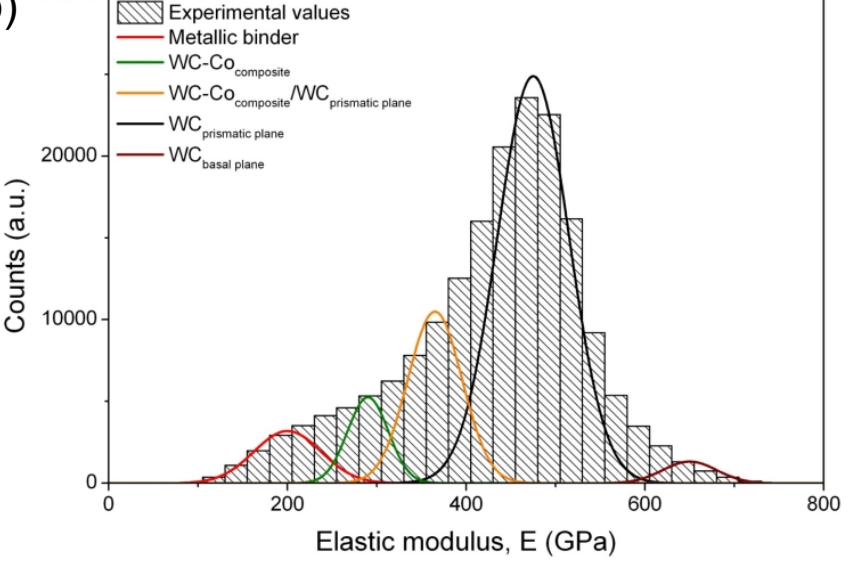

(c)
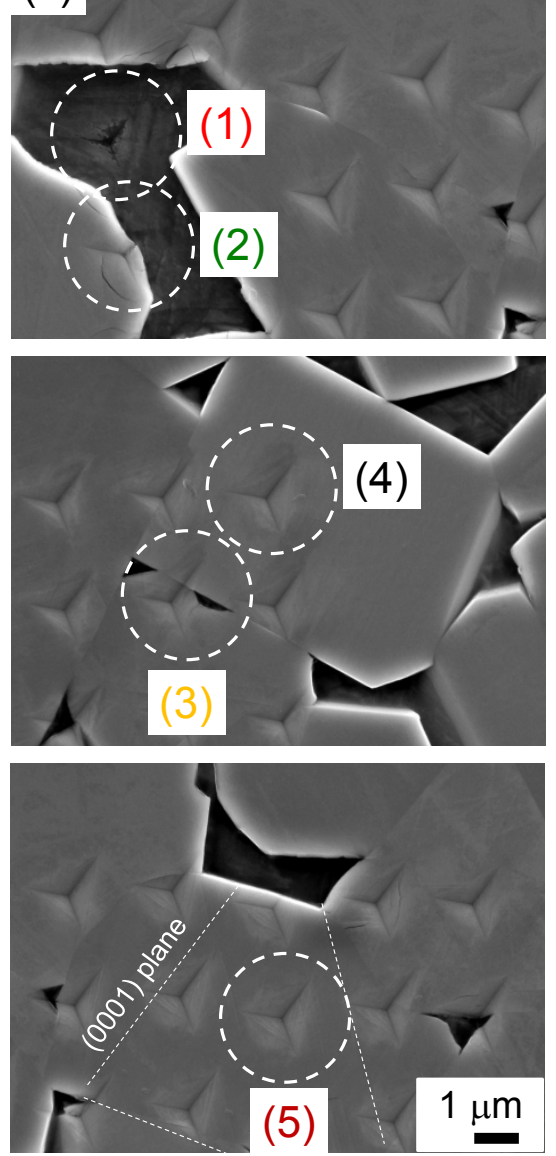

Figure 2 
(a)

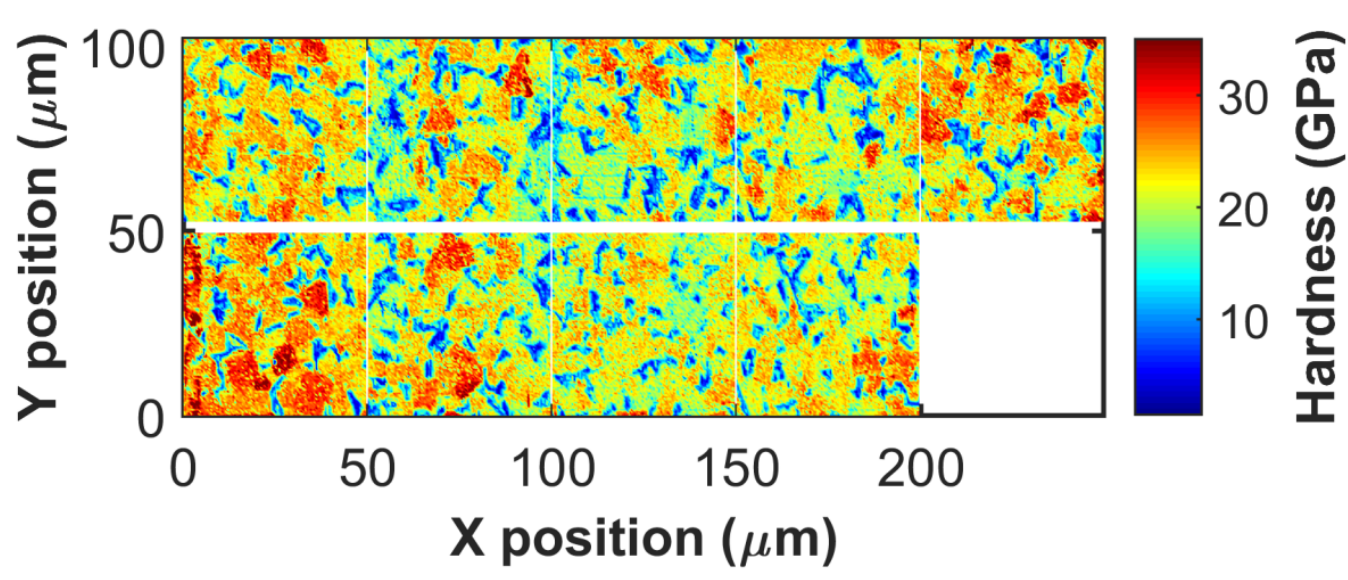

(b)

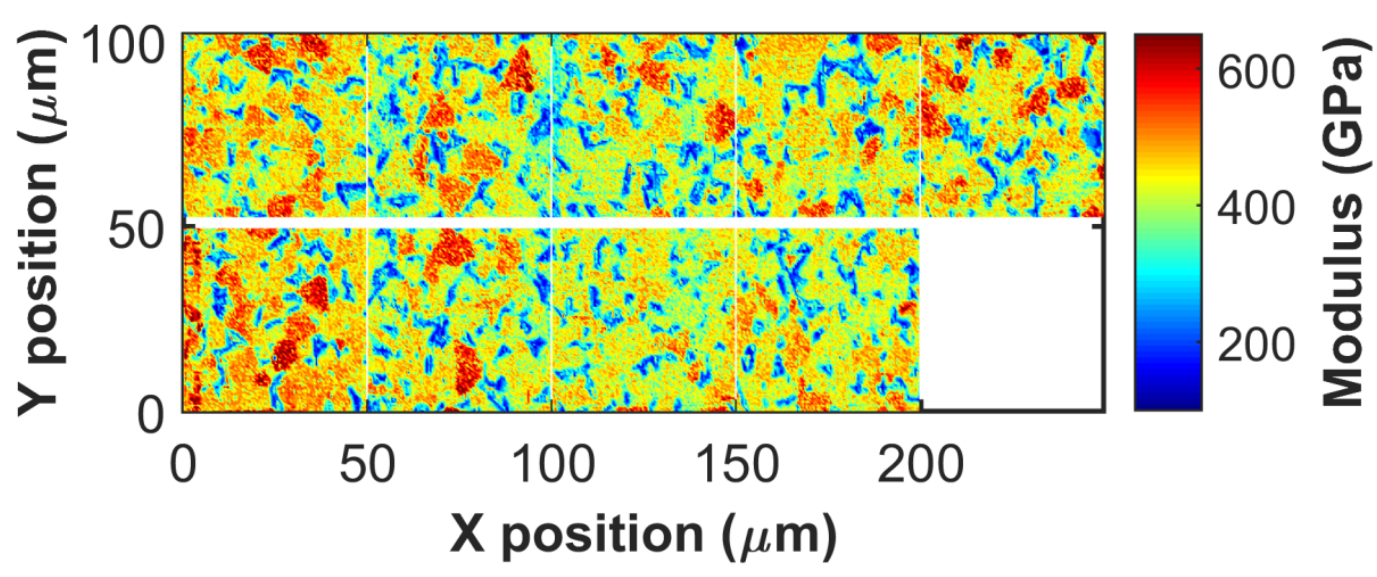

Figure 3 
Local

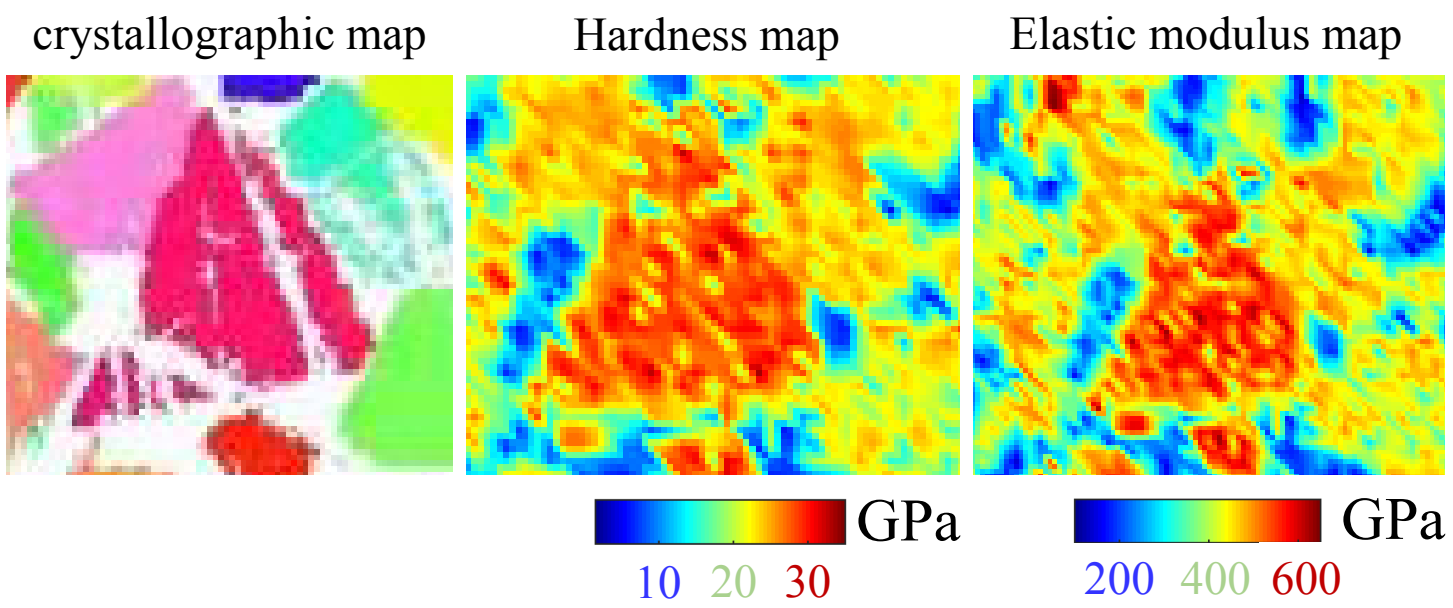

Figure 4 


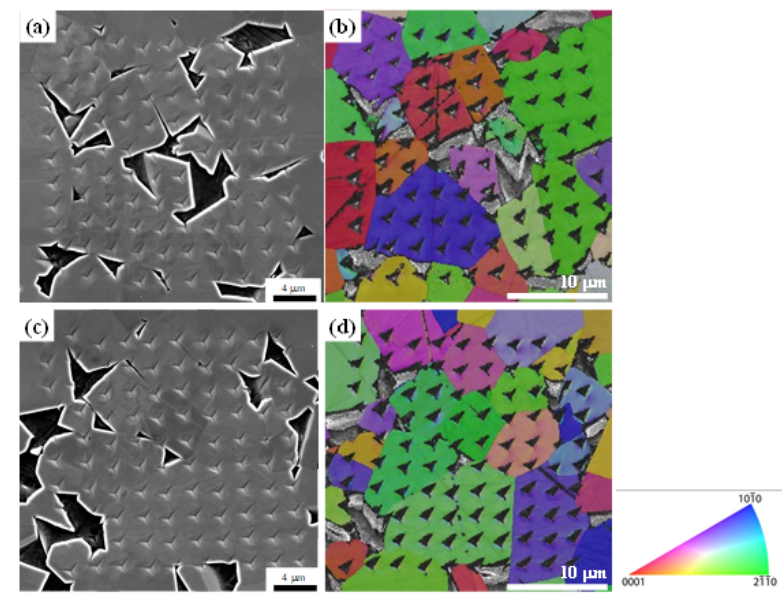

Figure 5 
(a)

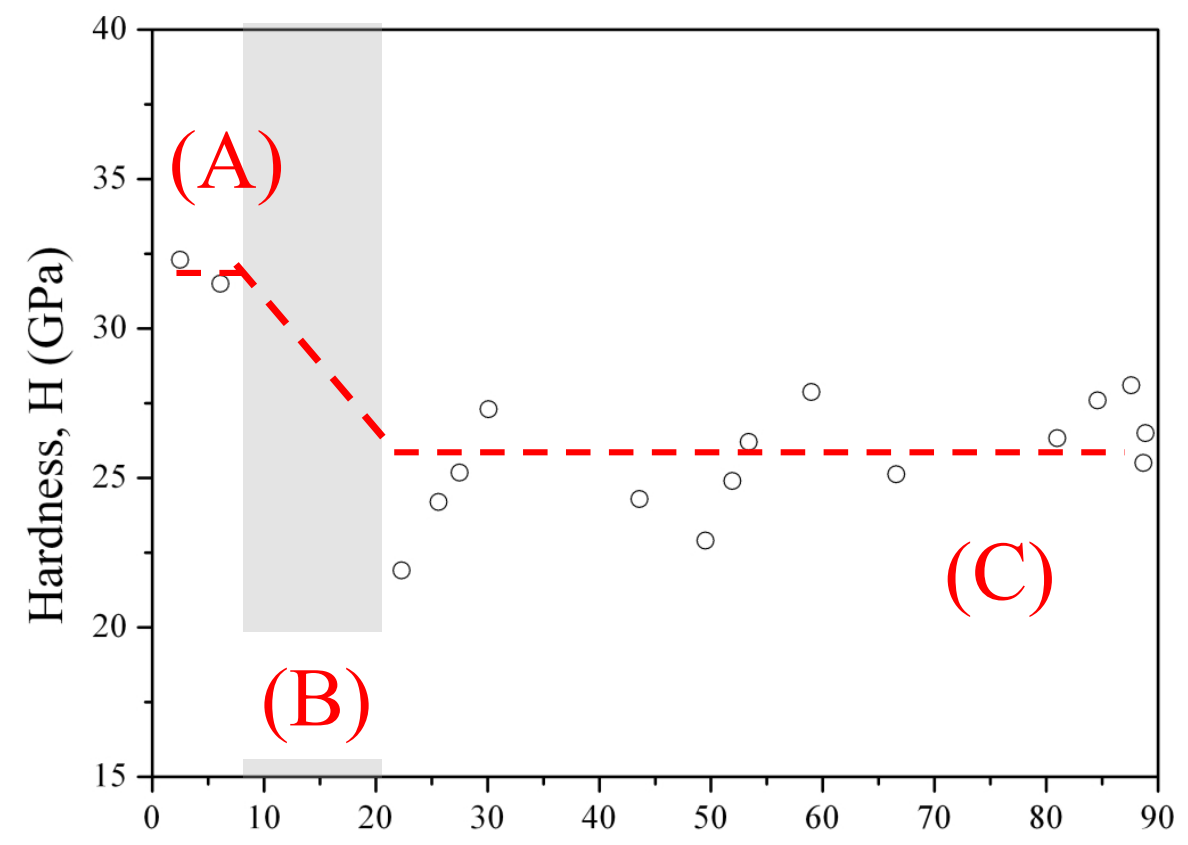

(b)

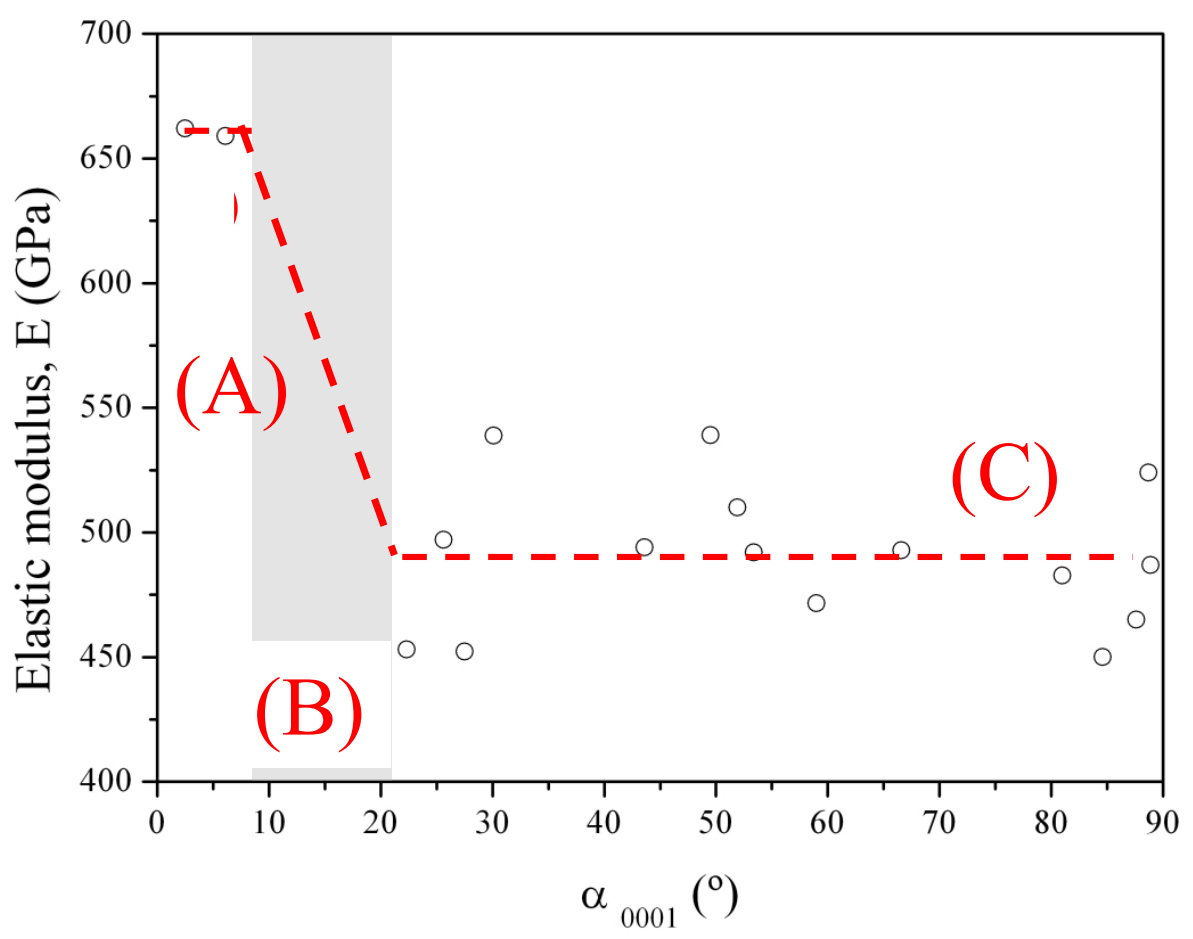

Figure 6 
(a)

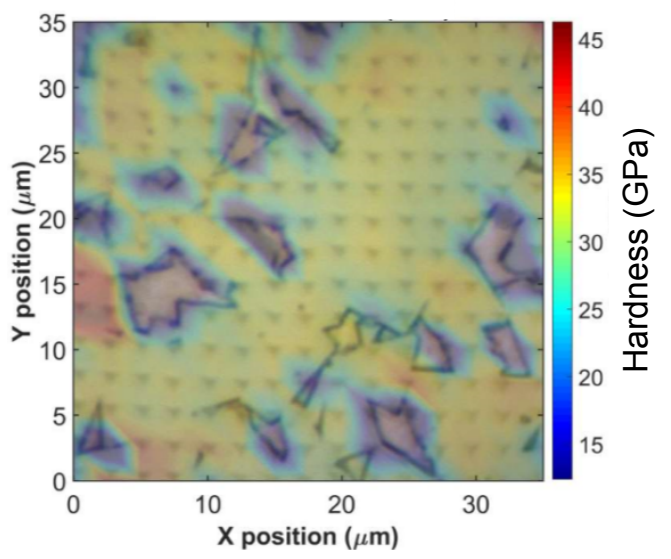

(b)

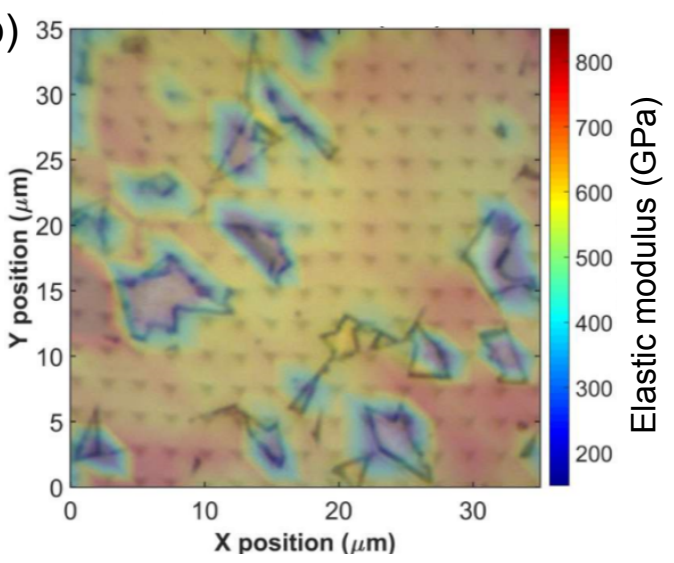

Figure 7 


\section{Table caption}

Tabla 1. Summary of the main microstructural parameters for the specimen investigated here (nominal weight fraction of binder, $\% w t$; ; mean grain size of WC, $d_{W C}$; mean free path in binder, $\lambda_{C o}$ and carbide contiguity, $C_{W C}$ ).

Table 2. Summary of the hardness $(H)$, elastic modulus $(E)$ and standard deviation $(S)$ for the different deconvoluted peaks (metallic binder and ceramic particle carbides with different crystallographic orientations) obtained through the statistical analysis. 
Table 1

\begin{tabular}{|l|l|l|l|}
\hline$\%$ wt. Co & $\mathrm{d}_{\mathrm{WC}}(\mu \mathrm{m})$ & $\lambda_{\mathrm{Co}}(\mu \mathrm{m})$ & $\mathrm{C}_{\mathrm{WC}}$ \\
\hline 11 & $1.12 \pm 0.71$ & $0.42 \pm 0.28$ & $0.38 \pm 0.07$ \\
\hline
\end{tabular}


Table 2

\begin{tabular}{|c|c|c|c|c|c|}
\hline Phase & Peak $^{*}$ & $H$ (GPa) & $S_{H}$ (GPa) & $E$ (GPa) & $S_{E}$ (GPa) \\
\hline Cobalt & 1 & 8.0 & 5.5 & 200 & 75 \\
\hline WC-Co composite & 2 & 14.0 & 4.5 & 290 & 45 \\
\hline WC-Co/WC $\mathbf{W r i s m a t i c}_{\text {e }}$ & 3 & 18.0 & 3.5 & 365 & 60 \\
\hline $\mathrm{WC}_{\text {prismatic plane }}$ & 4 & 25.5 & 5.0 & 475 & 80 \\
\hline $\mathbf{W C}_{\text {basal plane }}$ & 5 & 32.5 & 3.5 & 650 & 60 \\
\hline
\end{tabular}

* Peak number employed to denote each phase in Figure 2. 